\title{
Evaluation of Filler Distribution in Particulate Reinforced Composites
}

\author{
Kurganova Yuliya, Lopatina Yuliya, Yijin Chen \\ Department of Engineering Technology, Bauman Moscow State Technical University, Moscow, Russia \\ Email: kurganova_ya@mail.ru, lopatina.julia@yandex.ru, njust_chenyijin@163.com
}

Received 31 March 2015; accepted 24 June 2015; published 1 July 2015

\begin{abstract}
Aluminum matrix particulate reinforced composites are of significant interest to industry, but it's difficult to provide stable properties for this group of material. The mechanical properties of metal matrix composites are deeply influenced by the distribution of reinforcement particulates in the matrix. In this paper uniformity of SiC particles distribution in Al-based composites produced by stir casting and powder metallurgy technique is assessed. Analysis is carried out by means of classical and computer quantification metallographic image analysis methods. In addition, we suggest setting hardness distribution in cross section of samples as an indicator of reinforcement distribution uniformity in the matrix.
\end{abstract}

\section{Keywords}

Particulate Reinforced Composites, Metal Matrix Composites, Filler Distribution, Quantification Metallographic Analysis, Microhardness

\section{Introduction}

The ever rising of fuel price day to day has led to a renewed urgency to concentrate on the issue of weight reduction in the aerospace and automotive sectors. As monolithic alloys possess low strength to weight ratio, hardness, stiffness etc. so the area of application of these alloys restricted. This limitation has circumvented by incorporation of harder and stiffer ceramic particulates in the matrix, which is known as composite. Composites are significant for engineering materials due to their excellent mechanical properties over monolithic alloys. Aluminum and its alloys based metal matrix composites (MMCs) reinforced by silicon carbide particles are one of the widely known composites because of their superior properties such as high strength to weight ratio, hardness, stiffness, wear and corrosion resistances etc. over monolithic metals \& its alloys [1].

The distribution of particulates in MMCs is a major factor in determining the in-service properties of engineering components [2] [3]. Existing techniques of producing particulate reinforced MMCs are not perfect and cannot provide ideal filler distribution, so it's required to evaluate reinforcement distribution uniformity in the matrix [4]. 


\section{Experimental Procedure}

\subsection{Materials and Fabrication of Composites}

In the present experiment metal matrix composites including various volume fractions of SiC particles were produced by stir casting method and powder metallurgy technique. Set of specimens used in this study is given in Table 1.

For liquid state processing aluminum alloys AK12, AL25, V124 and D16 were used as the matrix material, while SiC particles with volume fraction 5, 10 and $15 \mathrm{wt} \%$ an average size of $28 \mu \mathrm{m}$ were used as the reinforcement material. For solid state processing aluminum alloys D16 and V95 were used as the matrix material, while SiC particles with volume fraction $20 \mathrm{wt} \%$ were used as the reinforcement material. The chemical composition of matrix alloys is given in Table 2. Powder metallurgy technique includes four steps: mixing of metal powder size $10 \mu \mathrm{m}$ and $\mathrm{SiC}$ particles in vibratory agitator, mechanical alloying (MA) in attritor, consolidation and extrusion [5]. Also there were some specimens with the same composition, but produced by modified technology without mechanical alloying.

\subsection{Metallography}

Analysis of filler distribution is carried out by means of classical and computer quantification metallographic image analysis methods. Samples for metallographic examination were prepared by grinding on Struers equipment. The microstructure observed by using optical microscope Olympys GX51F.

To determine phase fraction can be used different classical methods, e.g. method of M.A. Delesse, A. Rosival, A. A. Glagolev [6]. In the present research is used method of A. A. Glagolev: grid is drawn on the micrograph and number of dots which include phase is counted. Fraction of SiC particles can be calculated from the equation:

$$
C=A / B \text {, }
$$

where $C$ - SiC fraction, $A$ - number of dots which include SiC particles, $B$ - the total number of dots.

The size of micrographs was $270 \times 200 \mathrm{~mm}$, distance between gird's lines was $10 \mathrm{~mm}$, and consequently there were 588 dots on micrograph. The example of the image analysis by mean of A. A. Glagolev method is shown in Figure 1.

Since method of A. A. Glagolev is very laborious [7], only four micrographs of each sample MMC were studied. If computer quantification metallographic image analysis methods were used, efficiency would be increased. In the present research is used A. V. Zavodov's program for quantification analysis of material's micro-

Table 1. Set of spicemens.

\begin{tabular}{|c|c|c|c|c|c|c|c|c|}
\hline \multirow{3}{*}{$\begin{array}{l}\text { Method } \\
\text { Matrix }\end{array}$} & \multirow{2}{*}{\multicolumn{4}{|c|}{ Stir casting }} & \multicolumn{4}{|c|}{ Powder metallurgy } \\
\hline & & & & & \multicolumn{2}{|c|}{ With MA } & \multicolumn{2}{|c|}{ Without MA } \\
\hline & AL25 & AK12 & V124 & D16 & V95 & D16 & V95 & D16 \\
\hline SiC, vol\% & 5,10 & 5 & 10,15 & 5 & 20 & 20 & 20 & 20 \\
\hline
\end{tabular}

Table 2. The chemical composition of matrix alloys; Al-remained.

\begin{tabular}{cccccccccc}
\hline \multicolumn{7}{c}{ Matrix alloy } & \multicolumn{7}{c}{ The chemical composition } \\
\hline Russian & ISO 209:2007 & Si & Fe & Cu & Mn & Mg & Zn & Ti & Others \\
\hline AK12 & 4047 & $10-13$ & $<1.5$ & $<0.6$ & $<0.5$ & $<0.1$ & $<0.3$ & $<0.1$ & $\mathrm{Zr}<0.1$ \\
AL25 & - & $11-13$ & $<0.8$ & $<0.2$ & $0.3-0.6$ & $0.8-1.3$ & $<0.5$ & $0.05-0.2$ & $\mathrm{Ni} 0.8-1.3$ \\
V12 $<0.2$ \\
V12 & - & $8-11$ & $<0.3$ & $3-4$ & $0.1-0.3$ & $0.15-0.35$ & - & $0.1-0.3$ & $\mathrm{~B} 0.01-0.1$ \\
D16 & 2024 & $<0.5$ & $<0.5$ & $3.8-4.9$ & $0.3-0.9$ & $1.2-1.8$ & $<0.3$ & $<0.1$ & $\mathrm{Ni}<0.1$ \\
V95 & 7010 & $<0.5$ & $<0.5$ & $1.4-2.0$ & $0.2-0.8$ & $1.8-2.8$ & $5-7$ & $<0.05$ & $\mathrm{Cr} 0.1-0.25$ \\
\hline
\end{tabular}


structure [5] [7]. Screenshot of this program is shown in Figure 2. Using this program ten micrographs of each sample MMC were studied.

\subsection{Microindentation Hardness Testing}

Except metallography in the present research we suggest set hardness distribution in cross section of samples as an indicator of reinforcement distribution uniformity in the matrix. In the experiment the hardness of aluminium alloy composites were measured by Vickers micro hardness testing machine Emco-test Dura Scan 70 [8]. A series of ten measurements in increments of $0.5 \mathrm{~mm}$ is carried out on each sample with load $0.098 \mathrm{~N}$. The distribution of points for the measurement is shown in Figure 3.

\section{Results and Discussion}

The image analysis results are given in Table 3. For each sample dispersion of fraction value were found. Dispersion denotes how stretched or squeezed a distribution is. The image analysis results are showed that the

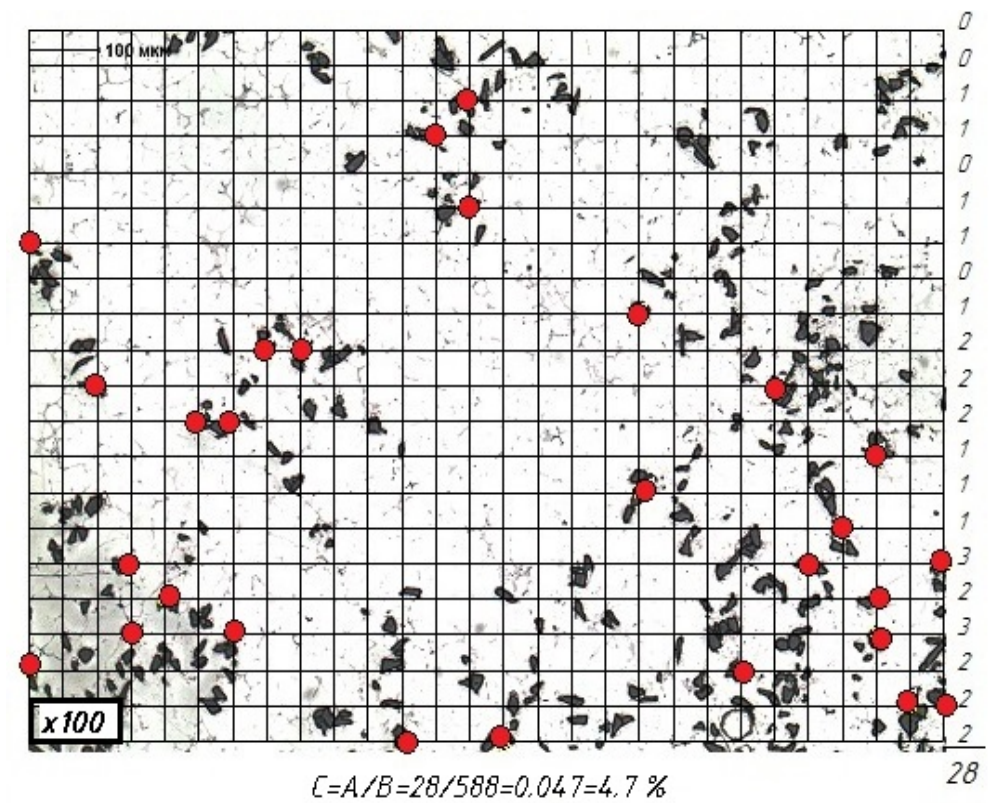

Figure 1. A. A. Glagolev quantification analysis method.

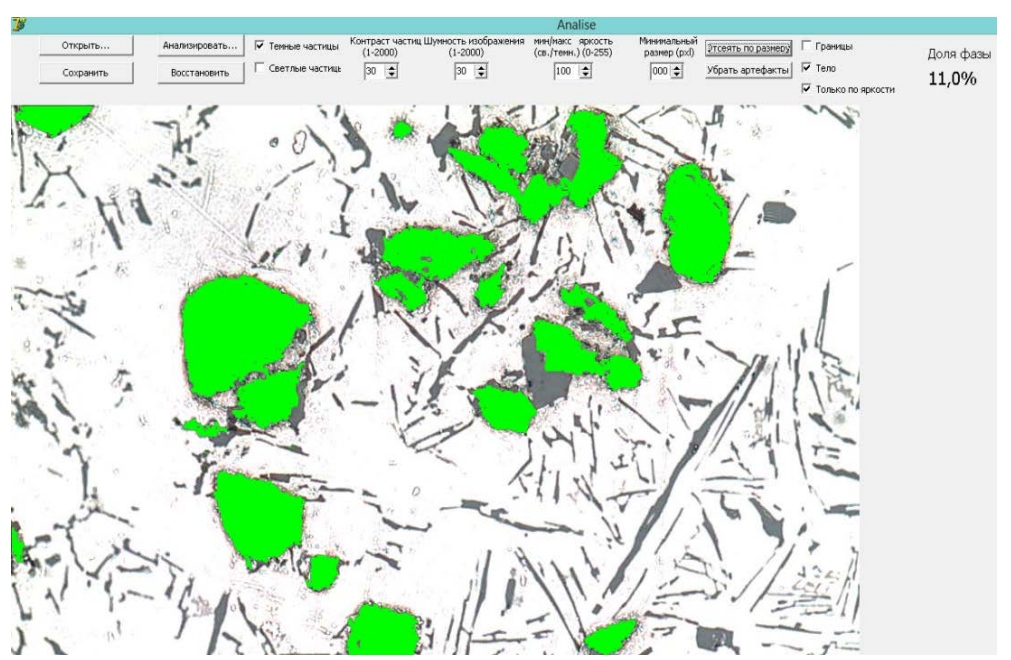

Figure 2. Screenshot of A. V. Zavodov's program for quantification analysis. 


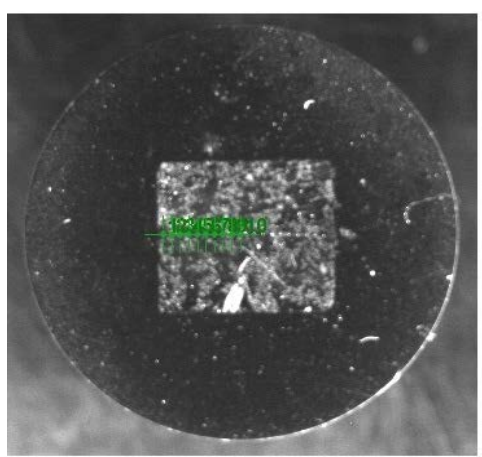

Stir casting

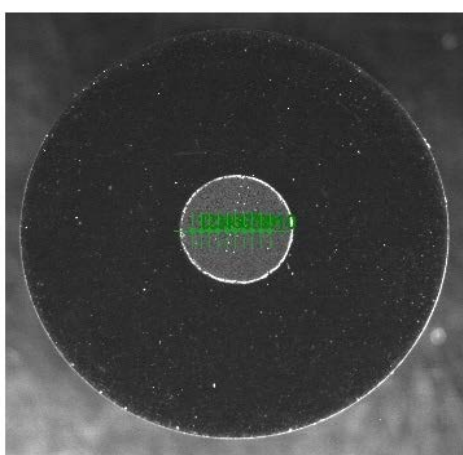

Powder metallurgy

Figure 3. The distribution of points for the hardness measurement.

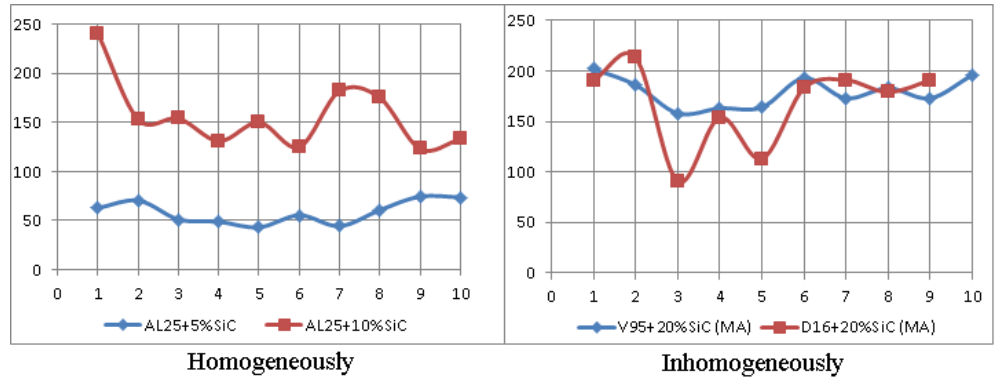

Figure 4. Hardness distribution in cross section fo the samples, HV.

Table 3. The image analysis results.

\begin{tabular}{ccc}
\hline \multirow{2}{*}{ Sample } & \multicolumn{2}{c}{ Dispersion } \\
\cline { 2 - 3 } & Method of A. A. Glagolev & Computer method \\
\hline AL25 + 5\%SiC & 2.03 & $0.82^{\mathrm{a}}$ \\
AK12 + 5\%SiC & 0.95 & 1.76 \\
D16 + 5\%SiC & 1.06 & 2.71 \\
AL25 + 10\%SiC & 1.82 & $0.44^{\mathrm{a}}$ \\
V124 + 10\%SiC & 0.55 & 1.82 \\
V124 + $15 \%$ SiC & 2.39 & 2.40 \\
V95 + 20\%SiC & 3.19 & 3.50 \\
D16 + 20\%SiC & 3.46 & 3.58 \\
V95 + 20\%SiC (MA) & 1.22 & $9.85^{\mathrm{b}}$ \\
D16 + 20\%SiC (MA) & 4.32 & $22.12^{\mathrm{b}}$ \\
\hline
\end{tabular}

distribution of $\mathrm{SiC}$ particles becomes more evenly with decrease of filler fraction. It can be seen that method of A. A. Gladolev demonstrates a similar results. The most uniform distribution is observed in samples with AL25 matrix. The worst uniform distribution is observed in samples produced by powder metallurgy technique with mechanical alloying step.

Figure 4 shows hardness distribution of homogeneously and in homogeneously samples. Significant variation of the hardness range in one specimen indicates the presence of particles agglomeration in one part of the sample and lack of particles in the other. Sharp, clearly visible jumps of hardness are observed in the case of direct penetration of the indenter into the SiC particle (Figure 5) and may be excluded from consideration. It can be seen that hardness distribution do not completely confirmed image analysis results. 

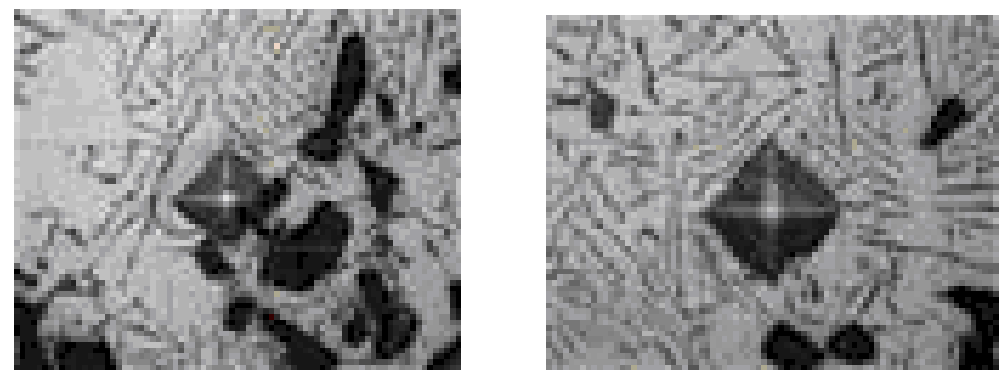

Figure 5. Penetration of the indenter into the SiC particle.

\section{Conclusion}

To conclusion the uniformity of distribution in all samples sufficient to provide desired level of properties. The most uniform distribution is observed in composites produced by stir-casting with low filler fraction. The worst uniform distribution is observed in composites produced by powder metallurgy technique with mechanical alloying step. Method of A. A. Glagolev demonstrates similar results to the computer method, but it is very laborious. Hardness distribution do not completely confirmed image analysis results, but it can be used for verification and validation.

\section{References}

[1] Rabindra, B., Nihar, R.M. and Sutradhar, G. (2012) Distribution of SiC Particulates in Stir Cast Aluminum Alloy Metal Matrix Composites and Its Effect on Mechanical Properties. International Journal of Emerging Trends in Engineering and Development, 2, 194-205.

[2] Chernyshova, T.A., Kurganova, Y.A., Kobeleva, L.I. and Bolotova, L.K. (2012) Dispersion-Strengthened Aluminum Matrix Composites: Production, Properties and Application. UISTU, Ulyanovsk.

[3] Chernyshova, T.A., Kurganova, Y., Kobeleva, L.I., Bolotova, L.K., Kalashnikov, I.E., Katin, I.V., Panfilov, A.V. and Panfilov, A.A. (2007) Composition Materials for Sliding Friction Pairs with Aluminium Alloy Matrix Strengthened by Particles. Konstruktsii iz Kompozitsionnykh Materialov, 2, 38-43.

[4] Kurganova, Y.A., Chernyshova, T.A., Kobeleva, L.I. and Kurganov, S.V. (2011) Service Properties of AluninumMatrix Precipitation Hardened Composite Materials and the Prospects of Their Use on the Modern Structural Material Market. Russian Metallurgy (Metally), 7, 663-666. http://dx.doi.org/10.1134/S003602951107010X

[5] Kurganova, Y.A. and Lopatina, Y.A. (2015) Analysis of Reinforcing Phase Distribution in Aluminum Matrix Composite Materials. Zagotovit. Proizv. Mashinostr., 4, 42-47.

[6] Saltykov, S.A. (1976) Stereometric Metallography. Metallurgy, Moscow.

[7] Lopatina, Y.A. and Kurganova, Y.A. (2014) Methods of Uniform Assessment of Reinforcement Distribution in Particulate-Reinforced Composite Materials. Proceedings of the XXVI International Innovation-Focused Conference of Young Scientists and Students (MIKMUS), Moscow, 17-19 December 2014, 213-217.

[8] Matyunin, V.M. (2005) Mechanical and Technological Tests and Properties of Structural Materials. MEI, Moscow. 